\title{
SURFACE MORPHOLOGY OF KIDNEY, URETERS AND URINARY BLADDER MODELS BASED ON DATA FROM THE VISIBLE HUMAN MALE
}

\author{
Zbyněk Tonar*a, František Zátura ${ }^{\mathrm{b}}$, Robert Grill ${ }^{\mathrm{c}}$ \\ a Department of Histology and Embryology, Faculty of Medicine in Pilsen, Charles University in Prague, Karlovarská 48, \\ 30166 Pilsen \\ ${ }^{b}$ Urology Clinics, University Hospital Olomouc, I. P. Pavlova 6, 77520 Olomouc \\ c Urology Clinics, University Hospital Královské Vinohrady, Šrobárova 50, 10034 Prague 10, Czech Republic \\ e-mail: tonar@lfp.cuni.cz
}

Received: September 20, 2004

Key words: Urinary system/Modelling/Biomechanics/Visible Human Project

The aim of the present work was to create a simplified high-resolution three-dimensional model of kidneys, ureters and urinary bladder in a data form suitable for finite element/volume based numerical simulations. The exterior morphology of the organs was based on images from the Visible Human Male data set. In both the right and left kidney, there were defined their topographic relations to the neighbouring anatomical structures. This model of kidneys, ureters and urinary bladder will be incorporated into the model of The Visible Human Male abdomen and pelvis and it is ready to be used for numerical simulations in urinary system biomechanics.

\section{INTRODUCTION}

Urinary tract anatomy has been already studied thoroughly and until now, several three-dimensional (3-D) models of the urinary system have been published ${ }^{3,11}$. These have been prepared with low or high resolution ${ }^{8}$, with or without details, ignoring or respecting relations to surrounding anatomical structures and with manual or semi/automatic segmentation methods. Some were even based on histological investigations ${ }^{6}$. However, the most important difference among the models consists in their purpose. Should the visualization be the primary goal of an anatomical reconstruction, the quality of the individual surface model elements is of less importance than the general appearance of the model. These models serve educational purposes, improving the understanding of construction principles of anatomic structures ${ }^{12}$, and for medical training, e.g. virtual endoscopy ${ }^{2}$. Should the reconstruction be intended for numerical simulation, the demands on the quality of the computational grid generated from the surface mesh become extremely high, because even the finest defect or inconsistency of the model can cause the numerical simulation to crash.

The Visible Human Project ${ }^{(\mathrm{TM})}(\mathrm{VH})$ data sets were designed to serve as a public domain reference point for the study of human anatomy by providing data for testing medical imaging algorithms, to construct image libraries and to generate $3 \mathrm{D}$ images in varying degrees of complexity ${ }^{1}$. The ultimate goal of the VH is to link functional-physiological knowledge with an image library of structural-anatomical knowledge into one unified health information resource.
The aim of the present work was to create a simplified 3-D model of kidneys, ureters and urinary bladder in a data form suitable for finite element/volume based numerical simulations. As a part of the model preprocessing, there should be described the boundary conditions of both kidneys in accordance with their three-dimensional topographic relationships.

\section{MATERIAL AND METHODS}

A cost-free agreement with the National Library of Medicine (Bethesda, MD, USA) allowed us to download the VH Male data set (http://www.nlm.nih.gov/research/ visible/visible_human.html) consisting of 1871 images of axial anatomical cryosections with a 2048x1216 pixel resolution, which were taken at $1 \mathrm{~mm}$ intervals. The VH Male was a 39-year-old person, who had willed his body to the medical sciences. The subject had no known urological disease. We used the cryosection slices, starting at slice avm 1550 at the level of the superior border of left suprarenal gland and ending with slice avm1905 at the inferior border of the urinary bladder, a total of 355 consecutive slices.

We used the software Amira (TGS Europe, Merignac Cedex, France) and a PC to perform the whole process which comprised following steps: All the colour VH images were cropped to a rectangle bounding the body's surface and converted to 8 bit color depth without changing their resolution. The images underwent segmentation by labelling the surfaces of kidneys, ureters and urinary bladder with the use of a graphical tablet. The resulting set of 2-D contours was then reconstructed into a 3-D 


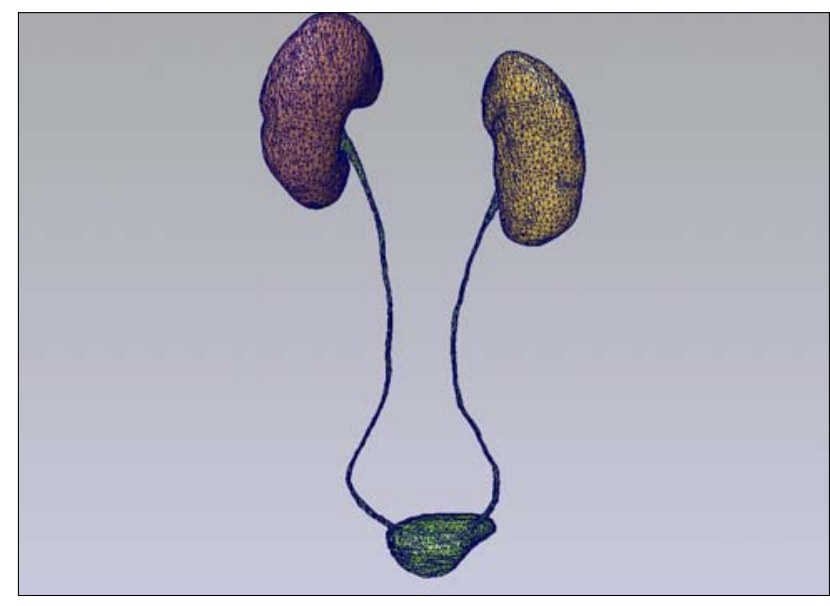

Fig. 1. Reconstruction of VH Male kidneys, ureters and urinary bladder, posterior view.

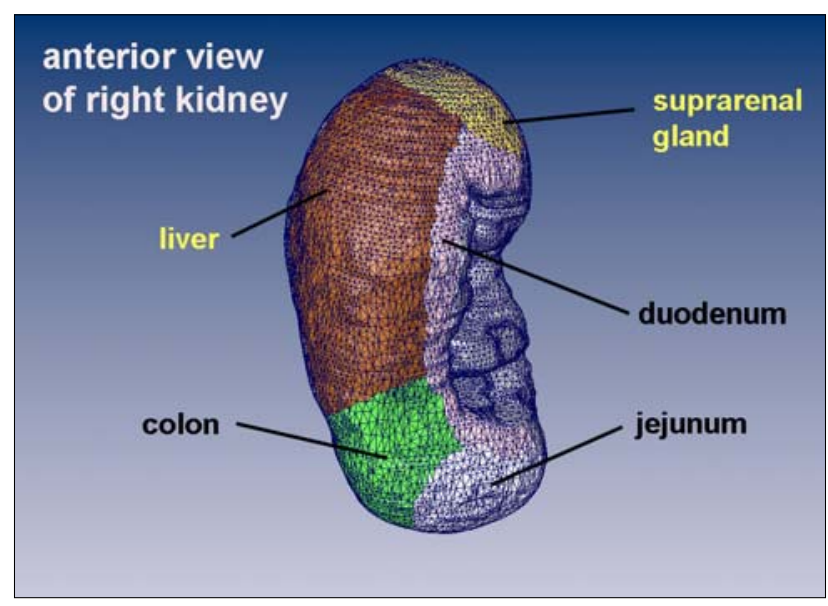

Fig. 3. Relations of the right kidney, anterior view.

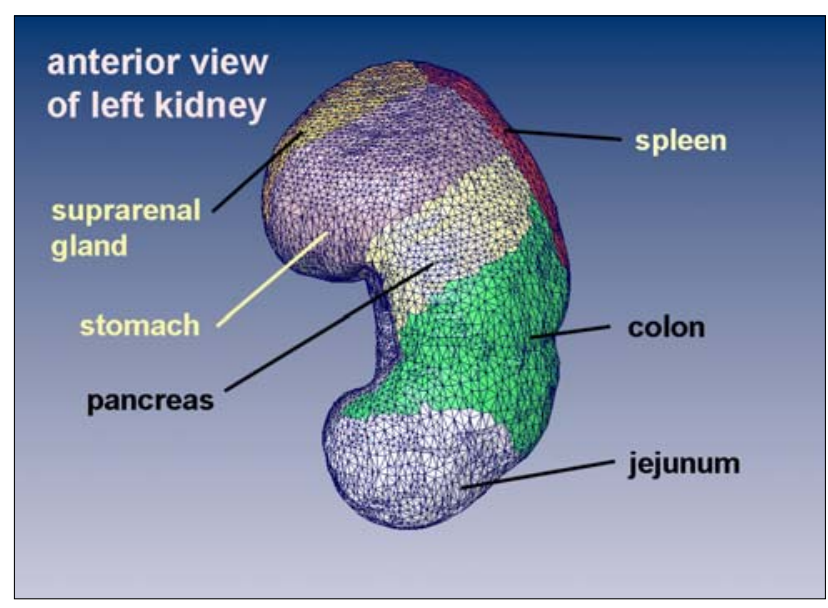

Fig. 5. Relations of the left kidney, anterior view.

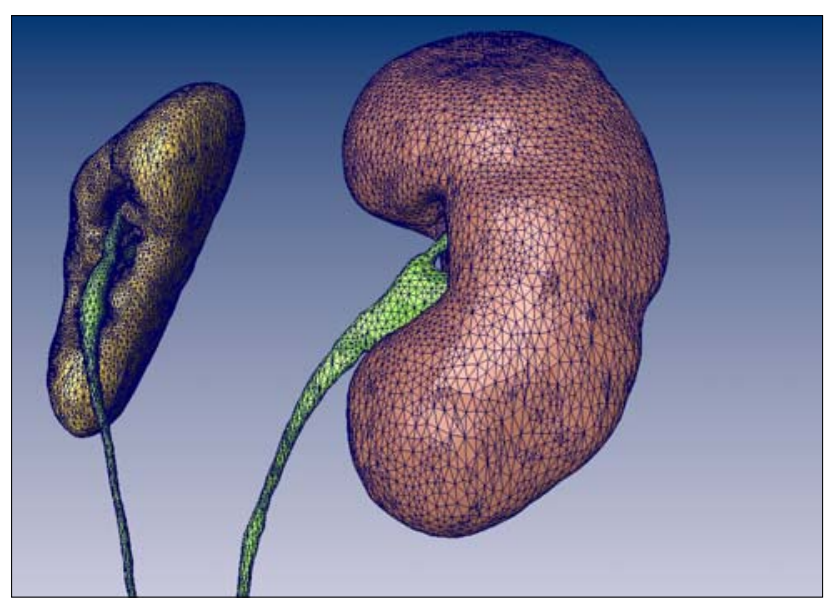

Fig. 2. Anterior surface of the left kidney and medial surface of the right kidney, left lateral view.

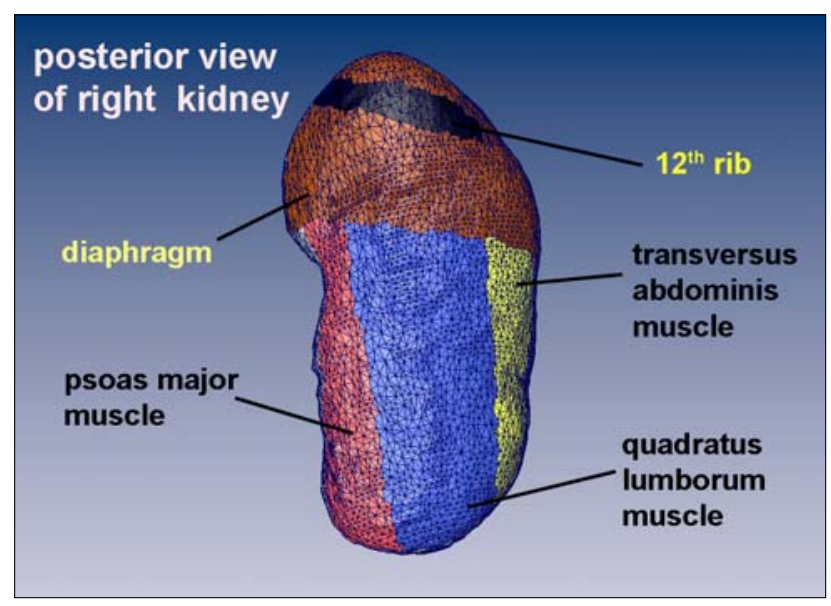

Fig. 4. Relations of the right kidney, posterior view.

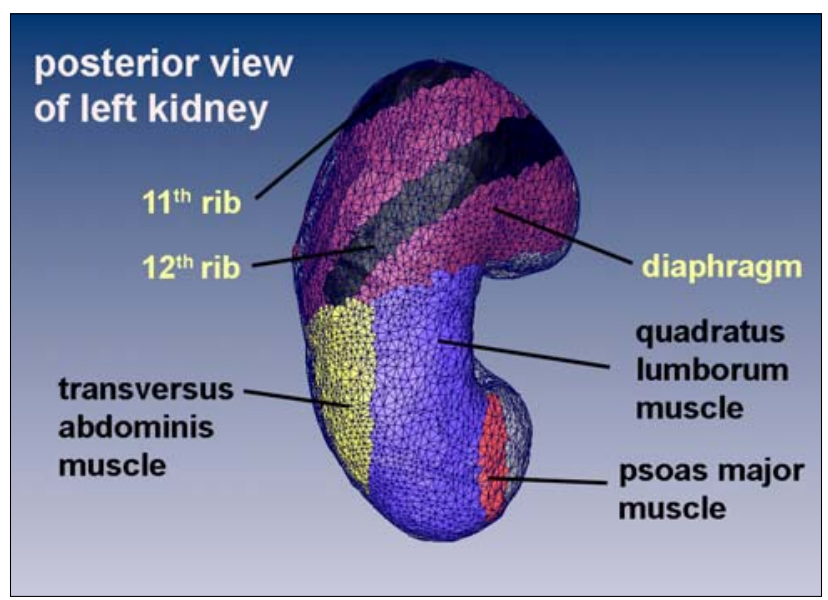

Fig. 6. Relations of the left kidney, posterior view. 
model. The set of surface polygons of kidney model was divided into subpopulations assigned to the surrounding kidney-related anatomical structures. In the last step, the triangular surface model was transformed into a finite-element mesh composed of tetrahedra.

\section{RESULTS AND DISCUSSION}

The anterior surface of right kidney (Fig. 3) is in contact with the right suprarenal gland. Below, there is a large hepatic area and a narrow area near the medial border is in contact with the descending part of the duodenum. Inferiorly the surface is in contact laterally with the right colic flexure, and medially with part of the small intestine. The posterior surface of each kidney (Fig. 4, 6) is embedded in fat. It lies upon the diaphragm, the psoas major, the quadratus lumborum, and aponeurotic tendon of the transversus abdominis. The right kidney rests upon the $12^{\text {th }}$ rib, the left on the $11^{\text {th }}$ and $12^{\text {th }}$ rib. The anterior surface of the left kidney (Fig. 5) has contact with the left suprarenal gland, spleen, stomach, and pancreas. Below the pancreatic and splenic areas the lateral part is in relation to the left colic flexure and the medial part with the first coils of the jejunum.

The size and proportions of some of the areas are very variable, particularly in the anterior surface of the kidneys. The results reflect very closely the relations presented by Seichert ${ }^{9}$ and Moore $^{7}$ and slightly differ from those of other anatomical textbooks ${ }^{4,13}$. The topographic relations, representing a part of the boundary conditions of the model, could be easily modified according to requirements of a particular simulation, e.g. describing the kidney relations during in/expiration, in the prone/supine body position or in the person sitting on a car seat.

The model can be used for crash test simulating the deceleration trauma sustained in a traffic accident. Another application could be the simulation of urine flow through the model. To perform the latter task, the wall and lumen of the ureters should be defined. The computer model of ureteric wall requires a morphometric quantitation study whose results should suggest an appropriate scheme of the simplified model of the ureter structure. A true model of the uretero-vesical junction is presumed to be the most difficult part of the model from a biomechanic point of view. For this reason it will probably require a 3-D histomorphological study ${ }^{5,10}$.

A serious limitation is that the data set is derived from one single individual. The inter-individual variability of organ shape and topology in space and time is thus not yet part of the model. Inclusion of variability into threedimensional models is a difficult problem not yet generally solved.

\section{CONCLUSIONS}

We presented an approach for creating a high-resolution model of the kidneys, ureters and urinary bladder, based on the Visible Human Male data. Due to the definiton of its spatial relations, it can be incorporated into the model of $\mathrm{VH}$ Male abdomen and pelvis and it is ready to be used for numerical simulations in urinary system biomechanics.

\section{ACKNOWLEDGEMENT}

This study was supported by the Grant GAČR 106/04/ 0201. We are grateful to the National Library of Medicine for the permission to work on the digitized sections of the $V H$ male and female.

\section{REFERENCES}

1. Ackerman MJ. (1998) The visible human project. Proc IEEE 86, 504-11.

2. Bajka M, Manestar M, Hug J, Székely G, Haller U, Groscurth P. (2004) Detailed anatomy of the abdomen and pelvis of the Visible Human Female. Clin Anat 17, 252-60.

3. Brooks JD, Chao WM, Kerr J. (1998) Male pelvic anatomy reconstructed from the Visible Human data set. J Urol 159, 868-72.

4. Čihák R. Anatomie 2. $2^{\text {nd }}$ edition. Prague: Grada Publishing, 2002. p. 261-5.

5. Dass N, McMurray G, Greenland JE, Brading AF. (2001) Morphological aspects of the female pig bladder neck and urethra: Quantitative analysis using computer assisted 3-dimensional reconstructions. J Urol 165, 1294-9.

6. Ganzer R, Neuhaus J, Dorschner W, Stolzenburg JU. (2002) Muscle systems of the lower urinary tract of the male rhesus monkey (Macaca mulatta): Histomorphology and 3-dimensional reconstruction. J Urol 168, 1603-7.

7. Moore KL, Dalley AF. Clinically oriented anatomy. $4^{\text {th }}$ edition. Philadelphia: Lippincott Williams \& Wilkins, 1999. p. 280-4.

8. Pommert A, Höhne KH, Pflesser B, Richter E, Riemer M, Schiemann T, Schubert R, Schumacher U, Tiede U. (2001) Creating a high-resolution spatial/symbolic model of the inner organs based on the Visible Human. Med Imag Anal 5, 221-8.

9. Seichert V. Močopohlavní ústrojí. Prague: Karolinum, 1997. p. 5-13.

10. Stolzenburg JU, Schwalenberg T, Do M, Dorschner W, Salomon FV, Jurina K, Neuhaus J. (2002) Is the male dog comparable to human? A histological study of the muscle systems of the lower urinary tract. Anat Histol Embryol 31, 198-205.

11. Temkin B, Acosta E, Hatfield P, Onal E, Tong A. (2002) Webbased three-dimensional virtual body structures: W3D-VBS. JAMA 9, 425-36

12. Venuti JM, Imielinska C, Molholt P. (2004) New views of male pelvic anatomy: Role of computer-generated 3D images. Clin Anat 17, 261-71.

13. Warwick R, Williams P, editors. Gray's anatomy. $35^{\text {th }}$ edition. Edinburgh: Longman, 1973. p. 1316-9. 